Faculty of Veterinary Medicine, Hama, Syria

\title{
APPLICATION OF IMMUNOHISTOCHEMISTRY TO DETECT CAMELPOX VIRUS IN CELL CULTURE AND HISTOLOGICAL SECTIONS
}

(With One Table and 4 Figures)

By

OMAR ALZIABI

(Received at 13/12/2006)

استخدام المناعة الكيميائية النسيجية للكثف عن فيروس جدري الجمال

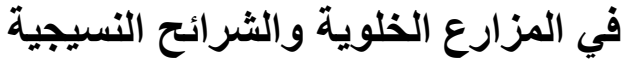

عر الزعبي

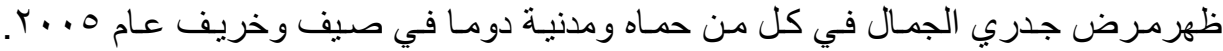

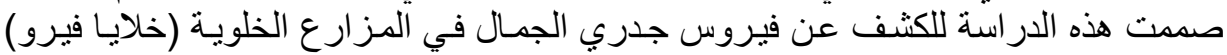

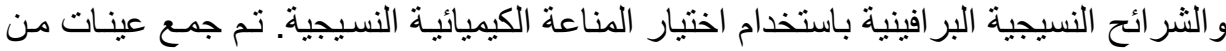

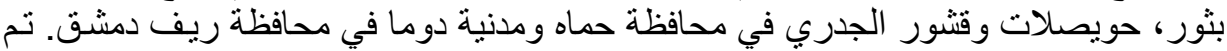

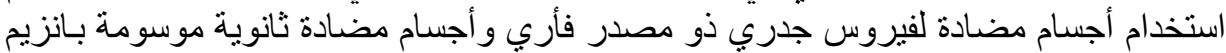

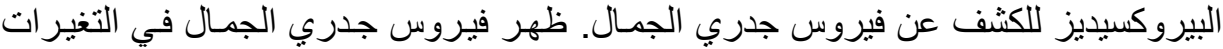

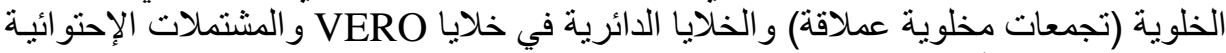

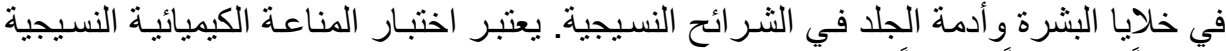

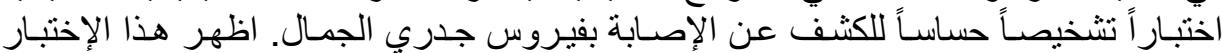

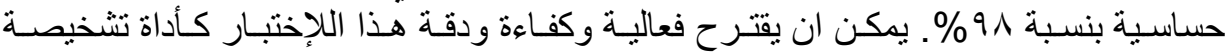
للإصابة بعدوى فيروس جدري الجمال.

\section{SUMMARY}

During the spring and summer of 2005, an outbreak of camelpox was spread in the province of Hama and Duma city. Therefore, this study was designed to detect camelpox virus in Vero cell culture and paraffin tissue section by immunohistochemistry. Skin samples (pustules, vesicles and scabs) from infected camels were collected from Duma and Hama. Monoclonal antibody (mouse anti-camelpox IgG) and labeled secondary antibody (rabbit anti-mouse IgG HRP) were used to demonstrate camelpox virus. Camelpox virus was localized in the cytopathic effects in cell culture (syncytia and round cells) and inclusion bodies in the dermal and epidermal cell of the skin. The present study shows that immunohistochemistry is a sensitive diagnostic technique to 
detect the infection in skin samples with sensitivity of $98 \%$ and reflects its effectiveness and accuracy in camelpox infection diagnosis.

Key words: Immunohistochemistry, camelpox virus, histology

\section{INTRODUCTION}

Camel husbandry in Syria constitutes less than 5\% from the total animal husbandry and poorly supported. Although, the Ministry of Agriculture had established 4 governmental stations in the past 25 years for camel husbandry and breeding. These farms contained 840 camels and more than 3000 camels in the private sector farms (Ministry of Agriculture newsletter, 2005). Moreover, camel's meat covered more than $25 \%$ of consumable red meat in some middle east countries such as Saudi Arabia (Wardeh, 1995). Therefore, animal health control and scientific research play a vital role in controlling animal disease and improving laboratory diagnostic techniques in order to protect the animal public health.

Camelpox occurs in almost every country in which camel husbandry is practised. The disease is endemic and outbreaks have been reported in the Middle East (Bahrain, Iran, Iraq, Oman, Saudi Arabia, United Arab Emirates and Yemen), in Asia (Afghanistan and Pakistan), in Africa (Algeria, Egypt, Ethiopia, Kenya, Mauritania, Morocco, Niger, Somalia and Sudan) and in the southern parts of Russia and India (Baxby 1972, Rosliakov 1972, Tantawi 1978, Falluji et al., 1979, Chauhan and Kaushik 1987, Hafez et al., 1992, Renner-Muller et al., 1995 \& Abu Elzein et al., 1999). Clinical manifestations of camelpox range from unapparent and mild local infections confined to the skin to moderate and severe systemic infections (Alhendi et al., 1994). The disease is characterised by fever, enlarged lymph nodes and skin lesions (Wernery et al., 1997 and 1999). Lesions appear 1-3 days after the onset of fever, starting as erythematous macules, developing into papules, vesicles, and pustules and later turning into crusts. Lesions first appear on the head, eyelids and nostrils and the whole head may be swollen. Later, skin lesions may extend to the neck, limbs, genitalia, mammary glands and perineum. In the generalized form, pox lesions may cover the entire body (Kriz 1982).

Skin lesions may take up to $4-6$ weeks to heal. In the systemic form, pox lesions can be found in the mucous membranes of the mouth, respiratory and digestive tract. The morbidity rate of camelpox is variable and depends on whether the virus is circulating in the herd 
(Kaaden et al., 1992). Transmission is by either direct contact or indirect infection via contaminated environment.

The virus is secreted in milk, saliva, and ocular and nasal discharges (Ramyar and Hessami 1972). The role of an arthropod vector in the transmission of the disease has been suspected. Camelpox virus belongs to the genus orthopoxvirus of the Poxviridae family (Tantawi et al., 1978, Renner-Muller et al., 1995) and is indistinguishable from the prototypic vaccinia virus in shape, structure, physico-chemical properties and replication (Gubser and Smith 2002) Transmission to humans is very rare but has been reported in non-vaccinated humans in Somalia (Jezek et al., 1983).

Although camelpox is existed since many years ago in many countries in which camel husbandry is practiced such as Middle East countries and Africa. There is no report or study which indicates the present of camelpox disease in Syria clinically or in the directorate of animal health laboratories. During the summer and Autumn of the year 2005 private sector farmers reported unknown disease with high mortality and morbidity and huge economic lost in their farms. Therefore, this study was conducted to detect camelpox virus in cell culture and tissue section and to describe the histopathological changes. Moreover, to evaluate immunohistochemistry technique as diagnostic test.

\section{MATERIALS and METHODS}

\section{Specimens}

In spring and summer of 2005,50 specimens of vesicles and pustules from affected camels were collected, in addition to 50 specimens of crusts and scabs from recovered camels. Specimens were divided into two pieces. For virus isolation the specimens were kept frozen at $-85^{\circ}$ whereas the rest of specimens were fixed for $24 \mathrm{hrs}$ in $10 \%$ (v/v) neutral phosphate buffered formalin $\mathrm{pH}$ (7.0) for histological tissue.

\section{Sample preparation}

Skin biopsy samples were homogenized with the FastPrepTM System (Q-biogene). Briefly, about $100 \mathrm{mg}$ of the biopsy sample were placed into a $1.5 \mathrm{ml}$ screw-cap tube containing a ceramic medium. After addition of $0.9 \mathrm{ml}$ minimal essential medium (MEM) with antibiotics (500 unit $/ \mathrm{ml}$ penicillin $\mathrm{G}$ sodium, $500 \mu \mathrm{g} / \mathrm{ml}$ streptomycin sulfate, and $1.25 \mu \mathrm{g} / \mathrm{ml}$ amphotericin B) the tube was shaken vigorously for $20 \mathrm{~s}$ in the FastPrep instrument. After a brief centrifugation step (1 min at 1,000 
$\mathrm{x} g$ ), the supernatant was used for cell culture inoculation. For virus isolation about $400 \mu \mathrm{l}$ of supernatant was inoculated onto a confluent monolayer of Vero cells grown in MEM containing 5\% fetal calf serum (FCS) and antibiotics (100 unit/ml penicillin G sodium, $100 \mu \mathrm{g} / \mathrm{ml}$ streptomycin sulfate, $0.25 \mu \mathrm{g} / \mathrm{ml}$ amphotericin B). After 1 hour at $37^{\circ} \mathrm{C}$, the inoculum was removed, and the cells were washed five times with 5 $\mathrm{ml}$ MEM before the addition of $5 \mathrm{ml}$ MEM containing 1\% FCS. Infected cells were incubated at $37^{\circ} \mathrm{C}$ and monitored daily for cythopathic effects. After 7 days cells were freeze-thawed twice and a $0.5 \mathrm{ml}$ aliquot from each sample was frozen to be used for 12 wells coverslips champers for immunostaining.

\section{Immunohistochemistry}

\section{A- Paraffin tissue section}

1- Paraffin sections of $4 \mu \mathrm{m}$ thickness were mounted on slides coated with Aminopropyltriethoxysilane (Merk, Allepo, Syria) then deparaffinised in xylene and rehydrated in 100\%, 90\% and 70\% alcohol, then washed in tap water for 10-15 min.

2- Endogenous peroxide activity was blocked by immersing the slides in $3 \%$ (v/v) $\mathrm{H}_{2} \mathrm{O}_{2}$ (Merk, Allepo, Syria) in methanol (Merk, Allepo, Syria) for $30 \mathrm{~min}$.

3- Intensive washing for $10 \mathrm{~min}$ in tap water then followed by two washes of $5 \mathrm{~min}$ each in $0.01 \mathrm{M}$ PBS pH $7.4(8.5 \mathrm{~g} \mathrm{NaCl}, 1.07 \mathrm{~g}$ $\mathrm{Na}_{2} \mathrm{HPO}_{4} 2 \mathrm{H}_{2} \mathrm{O}, 0.39 \mathrm{~g} \mathrm{NaH} \mathrm{PO}_{4} 2 \mathrm{H}_{2} \mathrm{O}$ and made up in distilled water to 1litre).Unmasking antigens.

4- Often paraffin sections fixed in formalin show masking or even destruction some antigenic epitopes. Slides were subjected to Microwave antigen recovery using retrieval solution $(0.01 \mathrm{M}$ sodium citrate buffer $\mathrm{pH}$ 6.0). Sections were then exposed to two or three 10 min cycles of microwave irradiation at $700 \mathrm{~W}$. Sections were allowed to cool at room temperature for $20 \mathrm{~min}$ followed by three washes of 5 min each in distilled water.

5- Two washes with PBS, the slides were blocked for $30 \mathrm{~min}$ at room temperature with inactivated normal rabbit serum (1 part NS: 3 parts PBS)

6- Sections were then incubated in a humidified chamber with mouse anti-camelpox virus (kindly provided by Dr El Harrak, BiopharamaMorocco) in PBS containing 25\% (v/v) skimmed milk. Negative controls were incubated with PBS containing 2\% (v/v) normal serum or IgG instead of the primary antibody. 
7- Following a further two washes in PBS of 5 min each; the slides were incubated for 30 min with rabbit anti-mouse HRP (Dako, Damascus, Syria) were used as secondary antibody with 1:100 dilution in PBS at room temperature in a humidity chamber.

8- Sections were again washed twice in PBS followed by visualization with $0.05 \%$ (w/v) 3,3'-diaminobenzidine (Dako, Damascus, Syria) in $0.01 \mathrm{M}$ PBS, $\mathrm{pH} 7.4$, and $0.01 \%(\mathrm{v} / \mathrm{v}) \mathrm{H}_{2} \mathrm{O}_{2}$.

9- The sections were finally washed in distilled water and counterstained with haematoxylin and dehydrated in graded alcohol, cleared in xylene and mounted in DPX.

\section{B- Cell culture}

Twelve wells chamber slides system so-called Lab-Tek II slide chamber slide system (Nalge Nune international, Japan) were cultured with VERO cell and inoculated with $0.1 \mathrm{ml}$ homogenized supernatant. When clear cytopathic effects (CPE) was observed, MEM media was removed and the wells were gently washed with PBS twice then fixed for $1 \mathrm{~min}$ in $4 \%(\mathrm{v} / \mathrm{v})$ neutral phosphate buffered formalin $\mathrm{pH}(7.0)$. The fixative was removed and the wells were gently washed in PBS for 10 min. the same procedure was used as above except step 2 and 4.

\section{Electron microscopy}

For confirmation of the virus identity homogenized supernatant were used for electron microscopic inspection. Staining was performed using negative counterstaining method for viruses.

\section{RESULTS}

\section{Histopathological changes and immunostaining:}

The CPE appeared within 4-6 days in the first passage and 2-3 days in the second and third passages. The distinctive feature of the CPE was the formation of massive numbers of large syncytia (Fig. 1A). The large syncytia eventually showed fragmentation and resulted in rounding cells with pkynotic or fragmented nuclei (Fig. 1B). However, the syncytium was formed after one of cells was infected and the virus multiplied in the cytoplasm (Fig. 1D). During replication of the virus, expression of the fusion protein at the cell membrane can result in the fusion of neighboring cells, and the formation of multi-nucleate cells or syncytia.

Histopathological examination of infected skin samples showed massive infiltration of dermis with neutrophils, macrophages and lymphocytes as well as oedema (Fig. 2A). The stratum spinosum had large satellite cells with intracytoplasmic eosinophilic inclusion bodies 
as well as vacuolation (Fig. 2 B \& C). Fig. 2D showed pox cells with invaded neutrophils. Crusts and scabs showed complete or partial necrosis in dermis and epidermis cells.

Immunostaining of infected cells in the cell culture chambers slide revealed diffused dark brown positive immunostaining in the antruim of syncytium (Fig. 3A), in addition to, round and pkynotic cells (Fig. 3B). There was no immune cross reactivity in the negative control (data not shown). Paraffin sections showed diffused numerous immunopositive cells in the pustules in the skin, lips and udder biopsies (Fig. 3C). Immunolabelled material was found in the epidermis with hydropic degeneration and inclusion bodies (Fig. 3D). Immuno-positive cells were detected in the vesicular fluid (Fig. 4A). Hair follicles and bulbs cells showed diffused immunostaining (Fig. 4B). Moreover, Histological sections from of crusts and scabs from recovered camel showed immuno-positive degenerated and necrotic cells and materials (Fig. 4C). Negative control slides showed no brown staining (Fig. 4B insert).

The comparison of infected camels with clinical symptoms and their specimens which been subjected to immunostaining revealed that all samples of vesicles and pustules were immuno-positive whereas crusts and scabs showed some immuno-negative samples and these samples failed to show any CPE when inoculated in VERO confluent monolayer (Table1).

\begin{tabular}{|l|l|l|l|l|}
\hline $\begin{array}{l}\text { Positive } \\
\text { immunostaining } \\
\text { cells }\end{array}$ & $\begin{array}{l}\text { Camels with } \\
\text { histopathological } \\
\text { changes and } \\
\text { inclusion bodies } \\
\text { in their cells }\end{array}$ & $\begin{array}{l}\text { Number of } \\
\text { camels with } \\
\text { clinical } \\
\text { symptoms }\end{array}$ & $\begin{array}{l}\text { Virus isolation } \\
\text { from infected } \\
\text { camels }\end{array}$ & Specimens \\
\hline 50 & 50 & 50 & 50 & $\begin{array}{l}50 \text { specimens from } \\
\text { infected camels } \\
\text { (vesicles and pustules) }\end{array}$ \\
\hline 48 & 48 & 50 & 50 & $\begin{array}{l}50 \text { specimens from } \\
\text { recovered camels } \\
\text { (crusts and scabs) }\end{array}$ \\
\hline
\end{tabular}

The sensitivity of immunohistochemistry technique can be evaluated using the international formula for measuring sensitivity $=$ No. of positive tested animals $\div$ No. of true positive animals + No. of false positive tested animals. In this study camel with clinical symptoms were considered as true positive animals infected with camelpox virus. Therefore, on the basis of the above formula the sensitively of immunohistochemistry technique $=98 \div 100+0=98 \%$. 


\subsection{Electron microscopy}

Inspection of homogenized scabs revealed orthopoxvirus particles with a typical brick-shaped appearance and irregularly arranged with clear tubular surface proteins (Fig. 4 D). 
Assiut Vet. Med. J. Vol. 53 No. 112 January 2007 
Assiut Vet. Med. J. Vol. 53 No. 112 January 2007 
Assiut Vet. Med. J. Vol. 53 No. 112 January 2007 


\section{DISCUSSION}

In this study, we have isolated camelpox virus and investigated the histopathological changes in cell culture and tissue sections and evaluated immunohistochemistry technique as a diagnostic test for camelpox infection. Camel pox infection can be diagnosed by clinical symptoms in combination with immunohistochemistry. Previously we have reported the sequencing of the amplicons and subsequent data analysis resulted in identification of the hemagglutinin open reading frame (ORF) which accounted for $948 \mathrm{bp}$ (the sequence has been submitted to Genebank with the accession number DQ853384). The HA ORF was compared to sequences of other orthopoxviruses published in GeneBank. At the nucleotide level the sequence obtained from the skin biopsy was $100 \%$ identical to camelpox virus strain Somalia and differed in one nucleotide only as compared to the HA sequence of camelpox virus strain Saudi Arabia (Alziabi et al 2006 in press).

Previously, we have also described the first epidemiological outbreak of camelpox in two provinces in Syria. Clinical symptoms started with fever, salivation and general exanthema. The main features were facial and legs oedema, pustules on the mucosa of the lips and a high rate of abortion. Lesions may also occur on the whole body including scrotum and udder. The morbidity ranged between 30-90\% and the mortality was about $1-15 \%$. There were no sheep or cows or humans in this outbreak (Alziabi et al., 2006 in press).

The distinctive feature of camelpox virus CPE was the formation of massive numbers of large syncytia. The large syncytia eventually showed fragmentation and resulted in rounding cells with pkynotic or fragmented nuclei. However, the syncytium was formed after one of cells was infected and the virus multiplied in the cytoplasm. These findings resemble many studies which cultivated camelpox in various cell culture types (Hafez et al., 1992, El-harrek et al., 1991, Chauhan and Kaushik 1987, Falluji et al., 1979 and Ramyar and Hessami 1972). Camel pox virus resembles some enveloped viruses such as measles virus, respiratory syncytial virus and mumps virus which possess a fusion protein in their envelopes to fuse with the host cell membrane and thus allow entry of the infectious genomic material into the cell cytoplasm. During replication of the virus, expression of the fusion protein at the cell membrane can result in the fusion of neighboring cells, and the formation of multi-nucleate cells or syncytia such as measles virus, respiratory syncytial virus and mumps virus (Gray, 1999). 
Histopathological changes in tissue sections are summarized in massive infiltration of leukocytes and oedema in dermis, necrosis in the epidermis and hair follicles cells, large satellite cells with eosinophilic intracytoplamic inclusions. Crusts and scabs showed complete or partial necrosis in dermis and epidermis cells. These results in agreement with previous studies in camels (Kinne et al., 1998, Pfeffer et al., 1998, Wernery et al., 1997 and Wernery et al., 1999)

Infected cells in the cell culture chambers slide revealed diffused dark brown positive immunostaining in the antruim of syncytium. Round and pkynotic cells were also immuno-positive. This may strongly suggest that the camelpox virus was localized in the antruim of the syncytium and in the round and pkynotic cells. However, paraffin sections showed diffused immuno-positive cells in the pustules and vesicles in the skin, lips and udder biopsies. Immunolabelled material was also found in the epidermis with hydropic degeneration and inclusion bodies. Hair follicles and bulbs cells showed diffused immunostaining. Moreover, Histological sections from of crusts and scabs showed immuno-positive degenerated and necrotic cells and materials. These results may indicate that immuno-positive contain the camelpox virus in their cytoplasm and considered to be the site of the virus in the infected cells. This may lead us to suggest that immunepositive staining of the infected cells reflects the histopathological changes in these cells, which means presence of the virus in these cells which exhibited pathological changes were immuno-positive by immunohistochemistry.

The present study shows that there were true association between the outcome of virus isolation and immunostaining outcome. The comparison of infected camels with clinical symptoms and the outcome of virus isolation and immunostaining revealed different scenario. Two specimens from recovered animals (crust and scabs) showed negative outcome for immunostaining and virus isolation. This may suggest some scabs and crusts may not contain camelpox viruses whereas specimens from infected camels (vesicles and pustules) found to have camelpox viruses. Therefore, the sensitivity of immunohistochemistry resulted in $98 \%$ as diagnostic test.

In conclusion, immunohistochemistry is a sensitive diagnostic technique to detect the infection in skin samples. The test showed a sensitivity of $98 \%$ which may suggest that the immunohistochemistry is sufficient, accurate and effective to diagnose camelpox infection. 


\section{AKNOWLEGEMENT}

This study was funded by JICA project at the Faculty of Veterinary Medicine in Syria and Special thanks for Dr Nishikawa JICA project Expert for his assistance and support and to Dr Kissling (Germany, Munchen University). The author would like to thank Dr Mohammad El- Harrak (Biophrama, Morocco) who supplied us with rabbit and mouse anti-camel pox virus.

\section{REFERENCES}

Alziabi, O.; Nishikawa, H. and Meyer, H. (2006): Outbreak of camelpox infection in Syria. Journal of Veterinary Medical Science (Japanese). In Press.

Abu Elzein, E.M.; Gameel, A.A.; Ramadan, R.O. and Housawi, F.M. (1999): An eruptive moderate form of camelpox infection in dromedary camels Camelus dromedarius) in Saudi Arabia. Review Science Tech, 18: 749-752.

Alhendi, A.B.; Abuelzein, E.M.; Gameel, A.A. and Hassanei, M.M. (1994): A slow-spreading mild form of camel pox infection. Zentralbl Veterinarmed, 411: 71-73.

Baxby, D. (1972): Smallpox-like viruses from camels in Iran. Lancet, 18: 1063-1065.

Gary, A.J. (1999): Assay for virus infection. Virus culture: A Practical approach. p81-109. Oxford University Press.

Chauhanm, R.S. and Kaushik, R.K. (1987): Isolation of camel pox virus in India. British Veterinary Journal, 143: 581-582.

Damaso, C.R.; Esposito, J.J.; Condit, R.C. and Moussatche, N. (2000): An emergent poxvirus from humans and cattle in Rio de Janeiro State: Cantagalo virus may derive from Brazilian smallpox vaccine. Virology, 277: 439-449.

El Harrak, M.; Loutfi, C. and Bertin, F. (1991): Isolation and identification of camel poxvirus in Morocco Annual Reserach Veterinary, 22: 95-98.

Falluji, M.M.; Tantawi, H.H. and Shony, M.O. (1979): Isolation, identification and characterization of camelpox virus in Iraq. Journal of Hygiene London, 832: 267-272.

Gubser, C. and Smith, G.L. (2002): The sequence of camelpox virus shows it is most closely related to variola virus, the cause of smallpox. J General Virology, 83: 855-872. 
Hafez, S.M.; Dl-Sukayran, A.; Dela, Cruz, D.; Mazloum, K.S.; AlBokmy, A.M.; Al-Mukayel, A. and Amjad, A.M. (1992): Development of a live cell culture camelpox vaccine Vaccine, 108:533-539.

Jezek, Z.; Kriz, B. and Rothbauer, V. (1983): Camelpox and its risk to the human population. Journal of Hygiene Epidemiology Microbiology and Immunology, 27: 29-42.

Kriz, B. (1982): A study of camel pox in Somalia. J Comparative Patholology, 92:1-8.

Kinne, J.; Copper, J. and Werenry, U. (1998): pathological studies on camelpox lesions of the respiratory system in the UAE. Journal of Comparative Pathology, 118: 257-266.

Ministry of Agriculture Newsletter (2005): General Organization of Agriculture Scientific Research report.

Pfeffer, M.; Meyer, H.; Wernery, U.; Kaaden, O.R and Meyer, $H$. (1998): diagnostic procedures for posvirus infection in camelids. Journal of Camel Practice and Research, 5:189-195.

Ramyar, H. and Hessami, M., (1972): Isolation, cultivation and characterization of camel pox virus. Zentralbl Veterinarmed B, 19:182-189.

Renner-Muller, IC; Meyer, H. and Munz, E. (1995): Characterization of camelpox virus isolates from Africa and Asia. Veterinary Microbiology, 45: 371-381.

Rosliakov, A.A. (1972): Comparative ultrastructure of viruses of camel pox, pox-like disease of camels "auzdyk" and contagious ecthyma of sheep. Vopr Virusol, 17: 26-30.

Tantawi, H.H.; El-Dahaby, H. and Fahmy, L.S. (1978): Comparative studies on poxvirus strains isolated from camels. Acta Virolology, 22: 451-457.

Werenry, U.; Kaaden, O.R. and Ali, M. (1997): Orthropox virus infections in dromedary camels in the united arab Emirates during the winter season 1995-1996. Journal of Camel Practice Research, 4: 51-55.

Werenry, $U$. and Zachariah, $R$. (1999): experimental camelpox infection in vaccinated and unvaccinated dromedaries. Journal of Veterinary Medicne B, 45: 131-135.

Wardeh, M.F. (1995): Proceedings of the workshop on the status of camel production and research in Algeria. Camel newsletters, 22-57. 